\title{
Photodegradation and photostabilization of historic silks in the museum environment - evaluation of a new conservation treatment.
}

\author{
Tatiana Koussoulou \\ Institute of Archaeology, UCL
}

\section{Introduction}

Silk fibres are believed to be the most sensitive of all natural fibres to deterioration caused by exposure to light in the museum environment. Modern museums use several methods to alleviate the problem: exclusion of natural light, controlled artificial light, UV filters on windows, specially-made cases and visitor-activated lighting. Another new method is the rotating display, which involves the replacement of objects by others of a similar nature, at regular intervals. However the problem still exists, as any kind of lighting, even controlled, causes deterioration. In historic buildings, with large windows and skylights, natural sunlight cannot be excluded, as it is part of the exhibition. When exhibitions are moved to different galleries and museums, historic textiles are also exposed to non-ideal conditions. The rotating display of objects cannot always take place because of the importance and rarity of some objects, which cannot be replaced with anything else. Finally, the installation of electronic lighting systems which are activated by visitors, and the invisible UV filters in specially-made cases, are expensive solutions applicable only to large and well-organized museums.

This paper explains the mechanisms of deterioration of the silk fibres and dyes used to make historic textiles displayed in museums, and introduces a new method of protection of historic silks by the application of materials known as light stabilizers directly to the objects. Testing of the suitability of these stabilizers, using silk fabrics dyed with traditional natural dyestuffs resembling the original historic objects, is also described.

\section{Historic silks}

Silk is one of the most important textile materials and highly valued as a luxurious and prestige fibre for its rarity, smoothness, gloss and bright colours. It is a natural animal fibre, usually coming from the moth larva Bombyx mori, which can be cultivated. There are also other types of silk fibres, like the Tussah silk, which is also called wild silk, as it cannot be cultivated and therefore is quite rare. The silk taken directly from the coccoon consists of two filaments stuck together and coated with sericin, a natural gum, which during the manufacturing process is dissolved and removed. This leaves two fibres, which are uneven in diameter along their length. Before the introduction of synthetic fibres, silk was often preferred for the preparation of royal clothing, clothing for special occasions, decorative textiles like embroideries, and ecclesiastical and ceremonial garments.

Silk's receptiveness to dyeing with natural dyes gives bright and shining colours, which was also an advantage, especially in association with the red dyes which give silk its royal identity. The sweet orange madder red, the delicate glistening safflower pink and the royal and sacred deep red cochineal, are some of the red shades 
commonly used in cultivated silk fibres in different cultures around the world, as in Asia and along the Silk Road, the Classical World, Egypt, Byzantium and later European civilizations (Scott 1993).

It is no surprise therefore, that silk textiles can be found in historic textile collections in museums all over the world. The problem that all these places are facing is the protection of historic silks from a very dangerous enemy, light. Silk is considered to be the most susceptible fibre to photodegradation (Becker et al. 1989; Harris 1984; Timar-Balazsy and Eastop 1998), the deterioration caused by any form of light, which leads to discoloration and weakening of the fibres and, of course, fading of the dyes.

\section{Light and its properties}

The sunlight reaching the earth consists of a continuous spectrum of radiant energy. The sun emits radiation of all wavelengths from x-rays $(<300 \mathrm{~nm})$ to infrared radiation $(>700 \mathrm{~nm})$, but fortunately the earth's atmosphere is almost completely opaque to radiation below $284-300 \mathrm{~nm}$. Of all the radiation emitted, the largest proportion (about $45 \%$ ) lies between $400-700 \mathrm{~nm}$ and is visible to the human eye, as visible white light. Radiation above $700 \mathrm{~nm}$ is invisible to the eye and is the infrared region of the spectrum. It is also referred to as radiant heat as the rays found in this region have a tendency to warm whatever they irradiate.

The shorter wavelengths of the solar spectrum, between $300-400 \mathrm{~nm}$ are also invisible to the human eye, and they are called ultraviolet light (UV). This ultraviolet light, which represents only $5 \%$ of the sun's electromagnetic radiation, is believed to be the most destructive portion of the solar radiation to all organic materials (Coleman and Reacock 1958; Brill 1980; Mills and White 1987; Nicholson 1991; Feller 1994; Timar-Balazsy and Eastop 1998).

Light consists of photons (bundles of energy) having wave characteristics. The photons with the shortest wavelengths have the most energy and they are found in the ultraviolet region of the spectrum. When a molecule of a polymer material absorbs ultraviolet light, the energy of the absorbed photon is conveyed to the absorbing molecule. If the amount of energy absorbed by the molecule is greater than the energies of the bonds present in its chain, these bonds will be broken, and the polymer damaged (Brill 1980; Mills and White 1987; Nicholson 1991; Feller 1994; Timar-Balazsy and Eastop 1998). In the following tables (Tables 1 and 2) the different wavelengths of the solar radiation, including the energy content of the ultraviolet light, are given together with the bond energy of the bonds usually found in organic compounds. It can be noticed that ultraviolet light has more than enough energy to break any polymer chain.

The breaking of the polymer chains can be described as photodegradation and can be explained in the following way. Every polymer has some light-absorbing groups of molecules, which absorb photons from light radiation; these groups are then raised to a higher energy level, referred to as an 'excited state'. The polymer molecule can discard the excitation energy in several ways that can be harmless, for instance by releasing energy as heat or by re-emitting light by fluorescence or phosphorescence. 
However some energy will be kept in the molecule, and will cause degradation. Although the number of excited molecules undergoing degradation is very small, solar ultraviolet light is capable of breaking a significant number of molecular bonds over the course of a year's exposure.

Table 1

Table 2

\begin{tabular}{|l|l|l|l|}
\hline Wavelengths (nm) & Energy (kJ/mol) & Bond type & \multicolumn{2}{l|}{ Energy (kJ/mol) } \\
\hline <400UV & $>300$ & CH3 - H & 427 \\
$400-430$ Violet & $300-277$ & CH3O - H & 419 \\
$430-490$ Blue & $277-247$ & CH3 -OH & 373 \\
$490-530$ Green & $247-223$ & CH3 - Cl & 344 \\
$530-590$ Yellow & $223-207$ & C2H5O - OC2H5 & 331 \\
$590-610$ Orange & $207-197$ & C2H5O - NO2 & 151 \\
$610-700$ Red & $197-176$ & C4H9O - OH & 151 \\
$>700$ Infrared & $<176$ & C4H9O - OC4H9 & 147 \\
& & CH3 - CH2O & 54 \\
\hline
\end{tabular}

Tables 1 and 2 Energy content of electromagnetic radiation and bond energies in organic compounds (Data taken from Timar-Balazsy and Eastop 1998: 17)

\section{Photodegradation of silk}

Silk fibre is considered to have the lowest resistance of all fibres to degradation from ultraviolet light. Radiation of a quite wide range of the spectrum of ultraviolet and sometimes higher visible light, can cause photodegradation of silk fibres (Harris 1984). It has also been noted that the lightfastness of a fibre is proportional to its diameter. The larger the diameter of the fibre, the better its resistance to photodegradation, as less radiation penetrates into the interior. It follows that one of the reasons that silk is the most fragile fibre under light exposure is the fact that it is the finest natural fibre.

As mentioned above, ultraviolet radiation is capable of breaking molecular bonds, when absorbed by the components of the fibres, causing what is known as photolysis. If the molecules of the fibres contain weak covalent bonds, visible light may also cause photolysis. Photodegradation starts with photolysis where an atom is separated leaving a very active radical. This radical reacts with atmospheric oxygen, which produces a polymer peroxide radical. This process is called photo-oxidation.

The poor-light fastness of silk can largely be explained by the presence of the amino acids phenylalanine, tryptophan and tyrosine in its composition. These amino acids have the tendency to absorb electromagnetic radiation and experience photooxidation easily. The degradation products of these reactions are chromophoric groups, resulting in the discoloration of the fibres. A number of photochemical 
reactions can occur between these oxidation products and the activated molecules of the amino acids present on the silk fibroin. These can involve the rupture of peptide bonds, hydrolysis (with the presence of high moisture in the fibre), or the introduction of cross-links in the polymer chain which result in a less elastic product.

The $\mathrm{pH}$ of the solutions used to treat silk during manufacturing processes is an important factor in the light stability of silk fibres. Silk is less resistant to light damage between $\mathrm{pH} 6$ and $\mathrm{pH} 8$. It has also been reported that silk shows its maximum light fastness at pH10 (Harris 1984; Timar-Balazsy and Eastop 1998).

An example of this is the finishing treatment of 'weighting' on silk that has been commonly used for the last 300 years throughout the world (Bogle 1979; Miller and Reagan 1989). The weighting process includes the application of $30-300 \%$ solutions of inorganic salts of aluminium, iron, lead, tin, or zinc to the fabric in order to increase the body and weight. This was performed primarily to increase the value of the fabric, as it was sold by weight and not by length. These weighting compounds are highly acidic, lowering the $\mathrm{pH}$ of the solution below 3 . Accordingly, it is obvious that weighted silks are more susceptible to photodegradation. The damage caused by strong acids to silk fibres is quite severe, and it has been shown that the effects of weighting on silk are much more deleterious under exposure to light than in darkness (Becker et al. 1987).

\section{The effect of light on dyes}

Natural dyes are organic polymers and their photodegradation reactions generally follow the same steps as fibres. By photodegradation of dyes, one usually means the fading of the dyes, which is the visual result of all the photochemical reactions that act in accordance and interference.

As dyes are coloured materials, they absorb certain wavelengths of the visible spectrum, and reflect those that can be seen as their colour. For example a red dyestuff reflects the wavelengths which represent the red part of the spectrum (610$700 \mathrm{~nm})$, whereas it absorbs all the rest.

With the absorption of electromagnetic radiation, a dye molecule is enhanced to an excited state. To return to its normal state, the dye molecule must dissipate the extra energy as heat or lower-energy radiation (fluorescence). This is what happens in the most light-fast dyes, whereas the majority of dyes, in their excited state and having major kinetic energy, undergo several photochemical reactions.

Although visible light does not have enough energy to break molecular bonds within the dye, ultraviolet radiation is often absorbed by the dye molecules. UV, as mentioned before, has more than enough energy to break certain bonds in the dye polymer chain, and this process is known as photolysis. If, during photolytic action, a chromophoric group of the dye is broken, there is a change in colour. The two separated particles have different colours, usually lighter ones which result in the fading of the dyed textile.

Photo-oxidation is the next step in photodegradation reactions in the case of dyes, as in fibres. The reaction with oxygen transforms parts of the chromophoric systems on 
the dye molecule into non-chromophoric groups. This results in the production of a lighter colour and thus a faded dye. The presence of high humidity accelerates the fading effect, as the atmospheric oxygen and moisture produce hydrogen peroxide. Hydrogen peroxide is an oxidizing bleaching agent.

There are a series of other reactions that can take place while the excited dye molecules try to dissipate their energy. These are dependant on the environmental conditions as well as the substrate, in this case the fibres. As the fibres themselves can absorb electromagnetic radiation, they can be photodegraded, giving degradation products ready to react with the dye molecules, and vice versa. These reactions are called phototendering and photosensitization and add a further dimension to the damaging effect of light on textile materials (Brill 1980; Mills and White 1987; Van Beek 1966).

\section{Light Stabilizers}

Having outlined the mechanisms of photodegradation, it is apparent that to achieve any form of photostabilization of historic textiles and dyes, the retardation or elimination of some photochemical reactions is desirable. A number of approaches to the photostabilization of polymers have been reported over the years (Bourdeau 1988; Carison and Whiles 1975; Coleman and Peacock 1958; Gantz and Sumner 1957; Kuramoto 1990; Lappin 1971; Randy and Rabek 1975; Shlyapintokh 1981; Tsatsaroni et al. 1998), all using materials called photodegradation inhibitors, photostabilizers, UV stabilizers or light stabilizers. Whatever the name of these materials, their action is focused on the termination or elimination of the effects of UV radiation on polymers, as the most destructive part of solar radiation. Some research has been done on using photostabilizers to prevent the fading of primarily synthetic dyes and colourants (Kehayoglou et al. 1997; Kitao 1991; Kuramoto 1990; Tsatsaroni et al. 1998). There have also been attempts to photostabilize natural organic materials such as wood (Williams 1983), and of course textile fibres such as cotton, silk and especially wool (Becker et al. 1989; Carr et al. 1985; Cegarra and Ribe 1972; Evans and Waters 1981; Head and Lund 1969; Leaver 1982; Reinert and Thommen 1991; Riedel and Hocker 1996; Walden and Moore 1961; Waters and Evans 1983; Waters and Evans 1980). All of these studies, however, have concentrated on the production of new, extremely light-fast fabrics to prevent the yellowing of the fibres and the fading of synthetic dyes, and have not addressed the issue of historic textiles.

Photodegradation inhibitors can be classified into three major groups, according to their mechanism of polymer photostabilization. These are the ultraviolet absorbers, the antioxidants and the excited state quenchers.

Ultraviolet absorbers, as their name indicates, are materials that absorb highly in the ultraviolet region of the spectrum. Their effectiveness is based on the blocking of ultraviolet light before it reaches the polymer; hence they are also called screening agents. Since the UV absorbers must be colourless, they should not absorb in the visible region, but must have a high absorption at 290 to $400 \mathrm{~nm}$, the ultraviolet section of the spectrum (Lappin 1971). 
There are many organic materials that may absorb in the ultraviolet region, but not all of them can act as UV stabilizers. An effective stabilizer, when irradiated and photoexcited, must have the ability to return to its ground state by disposing the excitation energy as heat. If the excited molecules of the stabilizer are capable of returning to the unexcited ground state very quickly, with the loss of heat energy, no photochemical reactions can occur.

Although there is no commercial absorber that has all of the above ideal characteristics, there are some commercial materials that perform quite satisfactorily in increasing the light-fastness of polymers.

The second, very important class of light stabilizers, the antioxidants, act in three different ways, according to their composition. As the name indicates, their photostabilization mechanisms are based on the elimination of photo-oxidation reactions. The first general mechanism, by which the antioxidants perform their stabilizing function, is as reactants with peroxide radicals. They compete with the polymer, in reacting with peroxide radicals, and in doing so prevent the photooxidation of the polymer caused by the reaction with peroxide radicals. Another mechanism by which the antioxidants work to stabilize polymers against photooxidation is 'radical trapping'. These materials trap alkyl and peroxide radicals without leaving the polymer to go through the propagation step of the photodegradation. A final way by which antioxidants act to stabilize polymers is through the decomposition of peroxides. The hydroperoxide groups in the photoexcited polymer undergo fragmentation during photodegradation reactions. Using antioxidants, this action is prevented as the peroxides are decomposed in a different way by the additive (Allen 1981; Becker et al. 1989; Nicholson 1991; Rytz et al. 1994)

The last category of photostabilizers, the excited state quenchers, deals with the photo-excited molecules of the polymers themselves. If the excitation energy of the irradiated polymer molecules can be transferred to the additive before any photochemical reactions can occur, the photostabilization of the polymer will be successful. The purpose of an excited state quencher is to receive the excitation energy of the polymer molecules and dissipate it harmlessly as heat. Transfer of excitation energy can happen through collision of the polymer and quencher molecules (Lappin 1971). The success of the quenching procedure is dependant, therefore, on the collision of the polymer and stabilizer molecules. This will happen if the excited state of the polymer molecule is prolonged for a period. Unfortunately this does not happen with all types of polymers and the quenching mechanism is thus not always successful. It is also known that the concentration of the quencher must be comparable to that of the polymer in order to produce the necessary collision of the molecules (Lappin 1971; Randy and Rabek 1975). This is a disadvantage of this type of stabilizers.

\section{Suitability for use on historic silks}

In order for a stabilizing agent to be suitable for application to historic textile materials, it must be colourless, meaning that it should transmit all radiation of the visible region of the spectrum, which effectively makes it transparent. It must not affect the colour or the texture of the substrate, or interact with the textile material in 
any harmful way. As Lappin (1971: 129) states “An effective stabilizer, must dispose of its excitation energy without interacting with the polymer in harmful ways and without undergoing any photochemical reaction which would destroy its effectiveness".

An important factor in the use of stabilizers in textile conservation is the method of application. The materials should be soluble in acceptable solvents for textile conservation, as used in other procedures like dry cleaning, whilst also not affecting the fibres or dyes. At the same time, the stabilizers must not interact with the solvent and must remain unchanged, in order to maintain their stabilizing characteristics. The $\mathrm{pH}$ of the solution must also be considered, as acidic solutions will cause irreversible damage to fibres (Landi 1985; Timar-Balasky and Eastop 1998).

Reversibility is also an important ethical issue in conservation and stabilizers must be easily removable from the textile, using simple, non-destructive, cleaning techniques. This is because any new material added to historic or archaeological objects may inhibit future analytical work, or cause problems if a new treatment is discovered which needs to be applied. That is why "a treatment must always be designed as a complete cycle of application, ageing and removal" (Horie 1987: 8).

\section{Materials and methods used}

In order to investigate the suitability of different photo-stabilizers for historic textile conservation, a number of experiments have been conducted by the author.

The silk fabric used for the experimental procedure was selected from the collection of Whaleys (Bradford) Ltd. (who produce 100\% silk for dyeing and printing), and is referred to as Habotai silk medium (S14). The fabric was made from cultivated Bombyx mori silk fibres with no dyes or finishes and was prepared with alum (aluminium sulfate) mordant prior to dyeing. Two different dyestuffs, madder and brazilwood, were applied with traditional dyeing techniques which involve the immersion of the fabric in a boiling solution of the dyestuffs in water. The selection of these two dyestuffs was based on their extensive use in museum textiles and their varying lightfastness. Madder dye is one of the most widely used dyestuffs because of its ease of application, its availability and its high light-fastness. Brazilwood gives an intense bright red colour on silk and it is also easily available, also being known as "redwood". Its light-fastness, on the other hand, is considered low, and it was therefore chosen for comparison with madder dye.

The stabilizing agents used were selected according to the recommendations of other researchers, being known to perform efficiently in treatments on polymer materials, plastics, synthetic dyes and wool fibres (Lappin 1971; Becker 1989; Jinjin and Griffiths 1990; Mason 1991; Riedel and Hocker 1996; Kehayoglou et al. 1996). The selection was also based on the commercial availability of the compounds, and their colour, toxicity, solubility and application methods. An attempt was made to select stabilizers from all the major categories, with different chemical structures. The materials selected are listed in Table 3 .

The method selected for the application of stabilizers onto the newly prepared samples was the immersion of each sample into the stabilizing solution. This is an 
acceptable method in textile conservation as it can be combined with the dry cleaning of textiles with organic solvents. In this way, the textile is not stressed at all and it can be hung up or left flat to dry in a few minutes.

The newly prepared silk fabrics were cut to $6 \times 6 \mathrm{~cm}$ squares. $2 \%$ solutions of stabilizers were prepared by dissolving $2 \mathrm{~g}$ of stabilizer in $100 \mathrm{ml}$ tetrachloroethylene solvent (solid in liquid). The samples were immersed in flat position in the stabilizer solutions and retained there for two minutes. For each sample fresh solution was used on each occasion. After immersion, they were removed and left to dry flat in glass dishes for twenty-four hours. During application, and while the samples were soaked in the solutions, no effect on the dyes was observed, as they did not 'bleed' in the solutions.

\begin{tabular}{|c|c|c|c|c|c|c|c|}
\hline & Tradenames $(s)$. & Chemical sincture & Category & Manufacturer & Solubility & Form & color \\
\hline A & . & 2-hydroxy-4-methoxy-benzophenone & absorber & Sigma-Aldrich & $\begin{array}{l}\text { insoluble in water } \\
\text { soluble in Tetractvene } \\
\text { insoluble in white spirit }\end{array}$ & $\begin{array}{l}\text { yellow } \\
\text { powder }\end{array}$ & light yellow \\
\hline B & - & $\begin{array}{l}\text { 2-hydroxy-4-n-octyloxy } \\
\text { benzophenone }\end{array}$ & absorber & Sigma-Aldrich & $\begin{array}{l}\text { insoluble in water } \\
\text { soluble in telrachl/ene }\end{array}$ & $\begin{array}{l}\text { yellow } \\
\text { crystals }\end{array}$ & light yeliow \\
\hline c & Tinuvin 327 & $\begin{array}{l}\text { 2.4-di-tert-butyl-6-(5-chlorobenzotria- } \\
\text { 20l-2-yl) phenol }\end{array}$ & absorber & Ciba & $\begin{array}{l}\text { insoluble in water } \\
\text { soluble in tetrach/ene }\end{array}$ & $\begin{array}{l}\text { yellowish } \\
\text { powder }\end{array}$ & light yellow \\
\hline D & Tinuvin 770 & $\begin{array}{l}\text { Bis }(2,2,6,6-\text { tetramethyli-4. } \\
\text { piperidinyl) Sebacale }\end{array}$ & $\begin{array}{l}\text { hindered } \\
\text { amine } \\
\text { Antioxidant } \\
\end{array}$ & Ciba & $\begin{array}{l}\text { insoluble in water } \\
\text { soluble in tetrachlene }\end{array}$ & $\begin{array}{l}\text { white } \\
\text { powder }\end{array}$ & transparent \\
\hline$E$ & Chimassorb 844 & $\begin{array}{l}\text { N,N'-bis(2,2,6,6-tetramethyl-4 piperidi } \\
\text { nyl)-1,6-hexane-diamine polymer with } \\
\text { 2,4,6-Inchioro-1,3,5-Irazine }\end{array}$ & $\begin{array}{l}\text { polymeric } \\
\text { hindered } \\
\text { amine } \\
\text { Antioxidani }\end{array}$ & Ciba & $\begin{array}{l}\text { insoluble in water } \\
\text { soluble in fetractlene }\end{array}$ & $\begin{array}{l}\text { transparen } \\
\text { crystals }\end{array}$ & $\begin{array}{l}\text { cloudy } \\
\text { while }\end{array}$ \\
\hline
\end{tabular}

Table 3 Stabilizers used in experimental treatments

After treatment the samples were exposed to electromagnetic radiation in order to evaluate the ability of the stabilizing agents to protect silk from photodegradation. An untreated sample (or "blank") was also exposed each time for comparison. As exposure to direct sunlight would be a long term procedure, and always vulnerable to external factors, such as the temperature and humidity of the environment and the intensity of radiation, the choice of an artificial light source, working in a controlled manner, was preferred. The samples were exposed in a Microscal unit following the British Standards method BS 1006:1990, UK-TN "Colourfastness to artificial light: mercury vapour fading lamp test" and method 2 (6.2.3).

The unit is a circular construction wherein the samples are exposed around an MBTL air-cooled lamp, each being equidistant from the lamp. MBTL lamps have been approved by several researchers as giving results closely comparable to those obtained in daylight exposure (Feller 1994; Giles et al. 1969; Park and Smith 1974; Park 1976). 
A Thermohygrometer recorded the environmental conditions during exposure. The samples were allowed to have regular intervals of darkness, every twenty-four hours, in order to regain their moisture content (the lamp used raised the temperature of the samples during exposure and therefore lowered the humidity). The colour difference produced in the samples was recorded every day, in comparison to the Grey scale and the reference Blue Wool Standards. The samples were exposed until the most resistant sample had reached Grey scale grade 3, following the (6.2.3.4) method of the BS 1006: 1990.

After exposure, the fading of the dyes on the treated and non-treated samples was evaluated by colorimetric measurements with a Minolta Chromameter. The evaluation was conducted by calculating the magnitude of the colour difference $(\Delta \mathrm{E})$ between the treated and untreated samples in the exposed and unexposed areas. The $\Delta \mathrm{E}$ is calculated by the three coordinates $\mathrm{L}, \mathrm{a}, \mathrm{b}$ which are used in the CIELAB colour system to describe any colour, and which can be measured by a colorimeter. The $\Delta \mathrm{L}, \Delta \mathrm{a}$ and $\Delta \mathrm{b}$ values represent the difference between the $\mathrm{L}, \mathrm{a}$ and $\mathrm{b}$ values before and after treatment and the magnitude of the colour difference is given by the equation:

$$
\Delta \mathrm{E}=\sqrt{(\Delta \mathrm{a})^{2}+(\Delta \mathrm{b})^{2}+(\Delta \mathrm{L})^{2}}
$$

\section{Results and Conclusions}

The colorimetric measurements after exposure of the treated samples, in comparison to the non-treated (Blank) sample are shown on the charts in Figures 1 and 2. The height of each column shows the rate of the fading of the dye, in the Blank sample first, followed by the treated samples. The higher the column, the bigger the colour difference, and thus the more faded the dye.

In both cases there are some promising results as the light-fastness on some treated samples is increased to a very satisfactory level in some cases. As mentioned above, two dyes were used on the same type of silk fibres, one very sensitive to photodegradation and the second more light-fast. In the case of brazilwood-dyed fabric, some increase of the lightfastness is noticed after treatment with the stabilizers A, B and E, with the maximum increase of $20 \%$ showed by B. The stabilizers C and $\mathrm{D}$, on the other hand, appear to cause photosensitization rather than photoprotection of the silk textiles as they decrease the lightfastness by about $2-5 \%$.

In the case of the madder-dyed silk samples, the results are rather impressive. All of the stabilizers seem to prevent fading of the dye to a considerable degree. An increase of $63 \%$ can be achived using the agent $\mathrm{D}$, while $\mathrm{A}$ also showed an significant increase of $50 \%$.

From these results it can be concluded that the prospects of using light-stabilizing agents in textile conservation are promising. The materials do not affect the fibres or the dyes, or the appearance or texture of the silk after application. Some of them proved to increase the light-fastness of the samples after exposure to electromagnetic radiation with two different dyes, one sensitive and one resistant. It should be noted however that the stabilizer $\mathrm{D}$, which shows the better performance on madder-dyed 


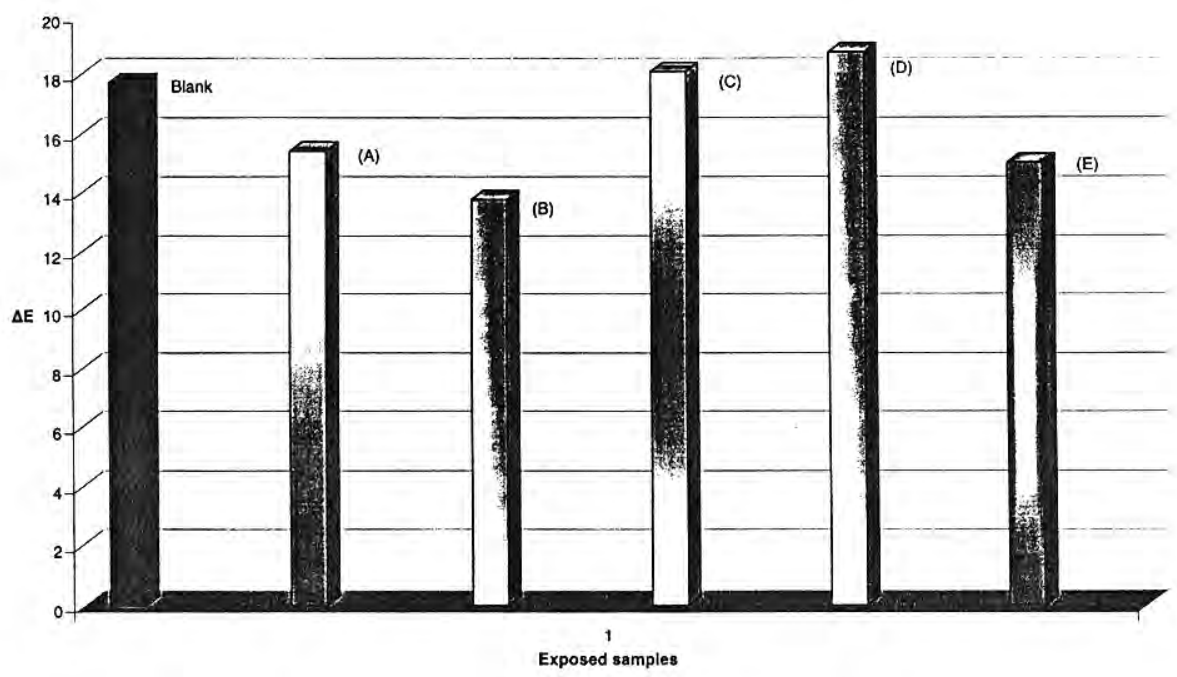

Figure 1 Colorimetric measurements for Brazilwood dyed silks

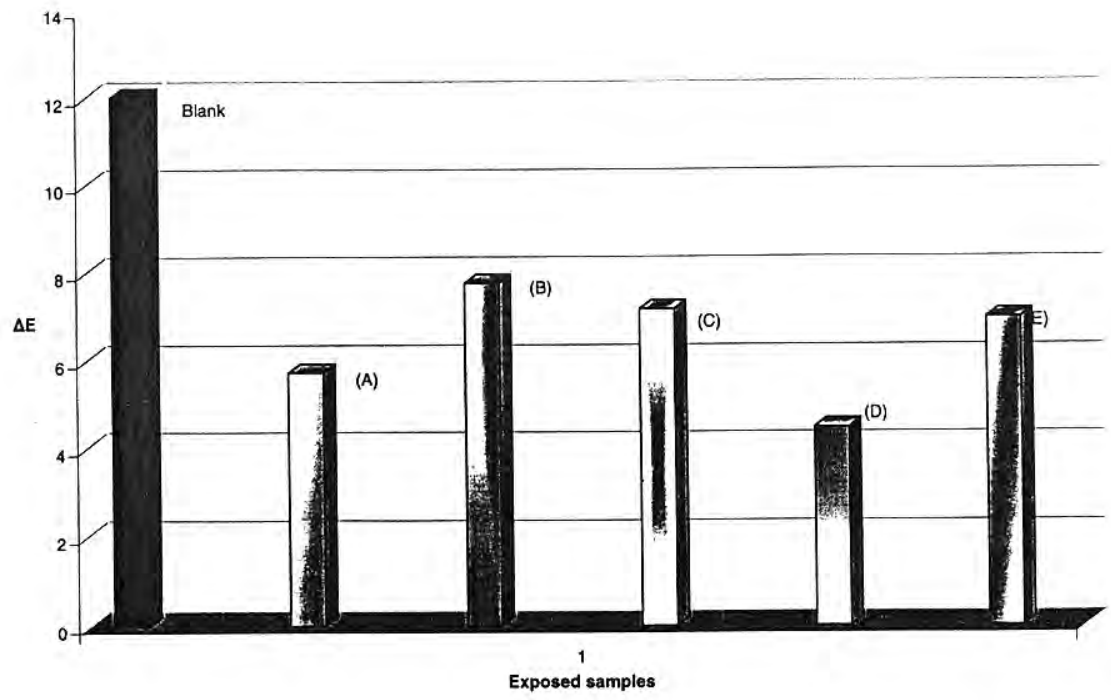

Figure 2 Colorimetric measurements for Madder dyed silks 
silks, also had the most negative results on brazilwood. This raises the possibility that different stabilizers would have to be used on differently-dyed silks.

More research is in progress on this new conservation treatment, using more dyes and dye-combinations, such as are more likely to be found in historic textiles. Furthermore, other stabilizing agents are undergoing testing together with other methods of treatment and varying concentrations, while the reversibility of the materials used is also under evaluation. Finally, study of the effects on the tensile properties of fibres will show the ability of light stabilizers to prevent fibre deterioration.

\section{Acknowledgements}

I would like to thank my supervisors in the Institute of Archaeology, Dr. Clifford Price, Mrs. Elizabeth Pye and Mrs. Diana O' Sullivan, for their useful guidance and advice during my research. Also, Mrs. P. Kavasila, Mrs. V. Romanou and Mrs. E. Papastavrou, from the Museum Of Folk Art, The Benaki Museum and the Byzantine Museum of Athens, for providing the original samples and important information from the collections of the above mentioned museums. In addition, many thanks to Dr. Jan Wouters from the Royal Institute for Cultural Heritage in Brussels, for his valuable help in the dye analysis of the historic samples; the Ciba Speciality Chemicals Co. for supplying samples of light stabilizers for testing; and Mr. Kevin Reeves for his perpetual help with the analytical equipment and his useful advice during the experimental work. Finally, Mrs. D. Pikopoulou-Tsolaki, Dr. Vincent Daniels, Mrs. Jenny Deen, Mr. Stuart Laidlaw and Mr. Harry Pratt, for contributions which have made this research possible.

\section{References}

Allen N.S. 1981. Photostabilizing action of hindered Piperidine compounds in commercial polymers, in Allen, N.S. (ed.). Developments in Polymer Photochemistry 2. London: Applied Science Publishers Ltd: 22-30.

Becker, M.A., Hersh S.P. and Tucker P.A. 1989. The Stabilization of silk to light and heat, in Needles, H.L. and Zeronian, H. (ed.). Historic textile and paper materials II. Washington DC: American Chemical Society: 94-106.

Becker, M.A., Hersh S. and Tucker P.A. 1987. The influence of tin weighting agents on silk degradation. Part I. Inorganic weighting agents in some historic silk fabrics of the $18^{\text {th }}$ and $19^{\text {th }}$ centuries, in Grimstad, K. (ed.). Preprints of the $8^{\text {th }}$ Triennial Meeting of the ICOM Committee for conservation. Los Angeles: Getty Conservation Institute (on behalf of the ICOM Committee for Conservation): 339-344.

Bogle, M. 1979. The deterioration of silk through artificial weighting. Textile Conservation Center Notes 11: 2-5.

Bourdeau, J. 1988. An examination of the barrier properties of selected UV absorbers within acrylic surface coatings in proceedings. Papers presented at the fourteenth Annual Art Conservation Training Programs Conference. May 45 1988. Art Conservation Dept. Buffalo State College : 41-61. 
Brill, B.T. 1980. Light, Its Interaction with Art and Antiquities. New York: Plenum Press.

Carison, D.J. and Whiles, D.M. 1975. The Photodegradation and Photostabilization of Polymers , a review. Journal of Radiation Curing 2: 2-14.

Carr, C., Leaver, M., Wilshire, J.K. 1985. A mechanistic study of benzotriazole UV absorbers as photoprotective agents for wool, in Proceeding of the $7^{\text {th }}$ International Wool textile research conference, Tokyo, Japan 1985: 50-59.

Cegarra, J.and Ribe, J. 1972. Use of 2,4-Dihydroxybenzophenone-2-ammonium sulphonate to prevent the yellowing of wool by UV radiation. Journal of the Society of Dyers and Colourists 88: 293-296.

Coleman, R.A. and Peacock, W.H., 1958. Ultraviolet Absorbers. Textile Research Journal 27: 784-791.

Crews, P. 1984. Evaluation of Ultraviolet stabilizers for use on Museum textiles. PhD thesis, Kansas State University, USA.

Evans, N.A. and Waters, P.J. 1981. Photoprotection of wool by application of Ultraviolet absorber-polymer mixtures to its surface. Textile Research Journal 51: 432-434.

Feller, L.R. 1994. Accelerated Ageing. Photochemical and Thermal Aspects. Marina del Rey: The Getty Conservation Institute.

Gantz, G.M. and Sumner, W.G. 1957. Stable Ultraviolet light absorbers. Textile Research Journal 27: 244-250.

Giles et al. 1969. Economical and efficient fading lamps. Journal of the Society of Dyers and Colourists 85 : 410-417.

Harris, M. 1984. The photochemical decomposition of silk. American Dyestuff Reporter 23: 403-404.

Head, F.S. and Lund, G. 1969. New ultraviolet absorbers for improving the stability of cotton cellulose to light. Journal of the Society of Dyers and Colourists 85: 61-65.

Horie C.V. 1987. Materials for Conservation. Oxford: Architectural Press.

Jingin, D. and Griffiths, J. 1991. Examination of the influence of stabilizers on the photochemical stability of disperse dyes, Journal of China Textile University 8 (2): 9-20.

Kehayoglou, A.H., Tsatsaroni, E.G., Eleftheriadis, I.C., Loufakis, K.G., Kyriazis, L.E. 1997. Effectiveness of Various UV-absorbers in Dyeing of Polyester with Disperse Dyes. Part III. Dyes and Pigments 34 (3): 207-218. 
Kitao, T. 1991. Photostabilizasion of colorants for imaging and data recording systems: Effect of metal carboxylates on the lightfastness of colour formers. Dyes and Pigments 16 (1): 1-10.

Kuramoto, N. 1990. Improvement in the light fastness of dyed and pigmented materials Part 3. The effect of antioxidants on the photostabilization of dyes and pigments in some polymeric media. Journal of the Society of Dyers and Colourists 106 (4): 135-138.

Landi , S. 1985. The Textile Conservator's manual. London: Butterworth \& Co.

Lappin, C.R. 1971. Ultraviolet Radiation Absorbers. Encyclopedia of Polymer Science and Technology 14: 125-148.

Leaver, I.H. 1982. The action of a benzotriazole light stabilizer in wool I. A diffuse reflectance analysis of UV screening, Journal of Polymer Science, Polymer Chemistry Edition 20: 2417-2427.

Mason, M.E. 1991. Design and Synthesis of lightfast disperse Dyes, in International Conference and Exhibition AATCC 1991: 114-121.

Miller, J.E. and Reagan, B.M. 1989. Degradation in weighted and unweighted historic silks. Journal of American Institute of Conservation 28: 97-115.

Mills, S.J. and White R. 1987. The Organic Chemistry of Museum Objects. London: Butterworths.

Nicholson, J.W. 1991. The Chemistry of Polymers. Royal Society of Chemistry paperbacks. Great Britain: Woolnough Bookbinders Ltd.

Park, J. and Smith, D.J. 1974. Comparison of sources for light fastness testing. Journal of the Society of Dyers and Colourists 90: 431-435.

Park, J. 1976. Rapid and economical testing of light fastness. International Dyer and Textile Printer 5: 220-223.

Randy, B. and Rabek J.F. 1975. Photodegradation, photooxidation and photo -stabilization of polymers. New York: Jon Wiley and Sons.

Reinert, G. and Thommen F., 1991. Lightfastness improvers and photostabilization of textiles, Textile Chemist and Colorist 23 (1): 31-37.

Riedel, J.H. and Hocker, H. 1996. Multifunctional Polymeric UV absorbers for photostabilization of wool. Textile Research Journal 66 (11): 684-689.

Rytz, G., Birbaum, J.L. and Steinmann, A. 1994. Light Stabilizers. Chimia 48 (9): 422-423.

Scott P. 1993. The Book of Silk. London: Thames and Hudson 
Shlyapintokh, V. Y. 1981. General Mechanisms of Polymer Photostabilization, in Allen, N.S. (ed.). Developments in Polymer Photochemistry. Manchester: Applied Science Publishers: 45-52.

Timar-Balazsy, A. and Eastop, D. 1998. Chemical Principles of Textile Conservation. Oxford: Butterworths.

Tsatsaroni, E.G., Kehagioglou, A.H., Eleftheriadis I.C. and Kyriazis, L.E. 1998. Effectiveness of various UV-absorbers on the Dyeing of Polyester with Disperse Dyes. Part IV, Dyes and Pigments 38 (1-3): 65-75.

Van Beek, H.C.A. and Heertjes, P.U. 1966. Fading by light of organic dyes on textiles and other materials, Studies in Conservation 11: 123-167.

Walden, W.C. and Moore, J.E. 1961. Comparison of ultraviolet light absorbers for protection of wool against yellowing. Textile Research Journal 31: 495-503.

Waters, P.J. and Evans, N.A. 1983. The abrasion-resistance of ultraviolet radiated wool: the effect of Benzotriazole photostabilizer. Journal of the Textile Institute 2: 99-100.

Waters, P.J., Evans, N.A. and Holt, L.A. 1980. The use of UV absorbers for reducing the chemical and physical damage caused by prolonged exposure of wool to light. Proceedings of the Quinquennial International Wool Textile Research Conference 5: 183-193.

Williams, S.R. 1983. Effect of grafted UV stabilizers on wood surface erosion and clear coating performance. Journal of Applied Polymer Science 28: 20932103. 